siological essays), the scientific assistant, as we shall call him, whose office was but recently, after a tenure of some years, vacated by the eminent pathological anatomist, Professor Schweigger, gives three different courses of instruction-one on ophthalmoscopy, another on the diseases of refraction and accommodation, and a third on the pathological anatomy of the eye. Professor von Graefe himself discourses on the diseases of the eye, as we have stated, three times a week, from ten to eleven o'clock in the morning. There were, on an average, from fifty to sixty hearers attending-among them always a number of qualified medical men. They are seated on chairs in two double rows, confronting each other, and leaving a passage between them for the patients presented, and particularly for the lecturer, who seldom occupies a seat, and ever and anon repairs to the black board, which, though moveable, rivals indeed the most stable of fixtures : it is his most cherished instrument of instruction, in the nse of which, whether lecturing, or conversing, or pausing from an operation, he is untiring, and the convenience of which he is very apt to suggest to any party conveying or seeking some information. The cases to be produced are, on the day preceding a lecture, selected by Von Graefe himself, or more frequently, under his direction, summoned by the junior clinieal assistant; who also, seconded by one of the male attendants, controls their movements to and from the lecture-room. A few minutes before the commencement of his lecture the professor spends in glancing at some of the cases in the anteroom. Some four or five of those among the students who believe themselves to be sufficiently advanced not to be listeners only, examine the cases previously to the lecture, in order to prepare themselves for the impending interrogatory. The lecturer does not profess within a given period to exhaust the whole subject of ophthalmology; his lectures are clinical in the received sense of the term. As cases emerge, or a series of cases, invested with practical interest, they are made the substratum of instruction. There is, however, scarcely anything of importance missed during the term; and whatever is taken up is certain to be exhaustively treated. The number of cases dwelt on in this manner are from two to five in the course of a lecture, towards the end of which as many or more are cursorily dealt with. Not unfrequently, the suggestion or request of a friend is sufficient for a subject to be made the item of discourse. The delivery of the lecturer is spirited in the highest degree, signalised by the most perfect ease and freedom, sometimes perhaps too rapid, though ever elevated in style. The tone is very frequently colloquial, and only becomes more measured when the teacher rises as it were with his subject-e.g., when he comes to treat on such chapters as paralytic disease, or the disorders of accommodation and refraction, or, especially, muscular asthenopia. We shall long harbour the impression we received when, having descanted in the most perspicuous strain on the last named very intricate and most interesting subject, he wound up his remarks by reminding us that the subject was one of the highest practical importance, and that the fathoming of it did honour to the human understanding. To my mind, this succinct peroration, most objectively pronounced as it was, enbodied the text of a panegyric such as in our day but few men might more rightfully claim than the speaker. We should, however, find it difficult to decide where his teaching was more instructive and suggestive; whether when he spoke on amblyopia, or when on the consistency of cataract, or, again, on the various forms of conjunctivitis and keratitis. We have once more been in the position lately of listening to teachers of great and deserved renown; but, thankful as we feel for many a valuable lesson, we did not fall in with any one who "had the elements so mixed in him".

[To be continued.]

ErRata. The following corrections are required in that part of Dr. Samelson's paper which appeared in the Journal of March 24th.

Page 306, col. Ir, line 28 from bottom, for " 10.20 ", read " $10.30 "$ ".

Page 306, col. Ir, line 8 from bottom, omit "many".

Page 308, col. II, line 15 from bottom, for "mentioned above", read "here mentioned".

Page 309, col. I, line 6 from bottom, for "invariably", read "invincibly".

\section{ON THE TREATMENT OF STRABISMUS WITHOUT OPERATION.}

By C. Houthousr, Esq., Surgeon to the Westminster Hospital, and to the Surrey Ophthalmic

Hospital, etc.

[Continued from page 252.]

Case IV. Double Convergent Strabismus of the Left Eyje to one Line, of the Right to three and a half Lines, from Paralysis of the Left External Rectus Muscle. Mary D., aged 52, married, came under my care at the Surrey Ophthalmic Hospital on August 17th, 1865 , for double convergent strabismus, which had made its appearance eight days previously, having been preceded by what seems to have been a slight conjunctivitis in consequence of cold; the eye being "bloodshot", slightly watery, and affected with "a pricking sensation", and the lids "gummy" in the morning. Two days after this inflammation had subsided, the patient was seized suddenly, in the middle of the day, with a severe shooting pain in the left eyeball, extending over the left side of the forehead and head and the upper part of the nose on the same side, together with much giddiness, confusion of vision, and diplopia, so that she had been afraid to trust herself to go about alone ever since.

Condition on Application. The above symptoms were still present with scarcely diminished severity. The eyeball was very tender on pressure, and its movements were painful ; but its tension was normal, and there was no vascularity of the sclerotic or conjunctiva. The pain over the forehead and head followed exactly the course of the supraorbital and supratrochlear nerves, pressure on which, at their points of exit from the orbit, caused much suffering. On examining the movements of the eje, the right being covered, they were found to be limited in the outward directions; $i$. e., the cornea could be brought exactly to a central position between the canthi, but not beyond; and the diagonal movements in an outward direction were defective. On the patient trying to look outwards, no action of the oblique muscles could be detected. The power of inverting the eye was perfect. On attempting to grasp a pen held a little to her left, she always clutched at it as if it were still more to her left than it really was. The pupil was of normal size, and responded readily to the stimulus of light. The eye was presbyopic to $\frac{1}{14}$; otherwise its vision was good-indeed, rather better than that of the right eye; for, whereas the latter had an acuity of vision of only $\frac{z}{3}$, the left was normal. The vision of the right eye was $\frac{20}{30}$, and with 30 lens, $\frac{20}{2}$, and that of the left eye $\frac{20}{20}$; so that the defect of sight of the right eye was due to hypermetropia. On closing the paralysed eye, the movements of the right eye and of its pupil were found to be perfect. 